\title{
Sinderos
}

\section{Perfil profesional de los agentes educativos que atienden primera infancia ${ }^{1}$}

\author{
Professional profile of early childhood educators
}

\begin{abstract}
Autora:
Nadia Milena Henao García

Recibido: 1 de febrero de 2018

Aprobado: 28 de febrero de 2018
\end{abstract}

\section{Resumen}

El artículo presenta el análisis de algunos de los resultados obtenidos en la caracterización del perfil profesional de los agentes educativos que atienden primerainfanciaenlaZona1(Nororiental) y Zona 2 (Noroccidental) de la ciudad de Medellín, enfocados en el conocimiento de la infancia que dichos agentes tienen desde una perspectiva histórica, política, de desarrollo y de derechos; para lo cual se aplicó una encuesta a docentes, auxiliares docentes, madres comunitarias, directivos y profesionales de apoyo pertenecientes a instituciones oficiales y privadas de las zonas en mención que ofrecen el Programa Buen Comienzo. La investigación se enfocó en el paradigma cuantitativo de tipo no experimental, descriptivo correlacional. Los resultados muestran, con respecto al conocimiento de la infancia, que existe un desconocimiento no generalizado de la categoría de infancia, es decir, se conocen elementos históricos, del desarrollo y la participación, pero no de manera amplia. 
Palabras clave: infancia, perfil belonging to institutions offering the profesional, agente educativo, Buen Comienzo program, officers concepciones, atención integral.

\section{Abstract}

The article presents an analysis of some of the results obtained in the characterization of the professional profile of educators attending early childhood in Zone 1 (Northeast) and Zone 2 (North West) of the City of Medellin, focused on knowledge of childhood these agents have a historical perspective, politics, development and rights, for which a survey of teachers, paraprofessionals, community mothers, managers and support professionals and private was applied of the zones in question. The research is focused on the quantitative paradigm of non experimental, descriptive correlational. The results show, with respect to knowledge of childhood, that there is not widespread ignorance of the category of childhood, elements of the historical, development, participation but not widely known, but focused on some agents educational.

Keywords: childhood, professional profile, educational agent, conceptions, comprehensive care.

\section{Introducción}

Desde 1968, Colombia inició acciones de política pública dirigidas a promover la protección de los niños con la creación del Instituto Colombiano de Bienestar Familiar (ICBF) mediante la Ley 75, tales acciones dieron vida a una concepción asistencialista, centrada en la protección y satisfacción de necesidades básicas como el cuidado y la nutrición, pero fue una visión alejada por mucho tiempo de concepciones educativas y pedagógicas. Fue así como nacieron los Centros de Atención Integral al Preescolar (CAIP) mediante la Ley 27 de 1974, orientados a la atención de los hijos e hijas de los trabajadores, a partir de allí se empezaron a gestar diferentes programas que buscaban no solo asistir al niño3 , sino generar espacios educativos (Simarra, 2010).

En la década de los ochenta, con la creación en 1986 de los Hogares Comunitarios de Bienestar (HCB), el país se acogió a los acuerdos internacionales en lo referente a la educación y atención a la primera infancia; en 1989 suscribió la Convención Internacional de los Derechos del Niño promulgada por la Unicef, que fue ratificada con la Ley 12 de 1991, este mismo año se ratificaron los derechos de los niños en el Artículo 44 de la nueva Constitución de Colombia, en el 2004 se inició la movilización por la primera infancia a través de la Alianza por la Política Pública de Infancia y Adolescencia en Colombia y en 2006 se promulgó la Ley 1098, Código de Infancia y Adolescencia.

Fue así como en el 2007 se formuló la Política Pública Nacional de Atención Integral a la Primera Infancia mediante el Conpes 109, la cual busca "promover el desarrollo

3. En adelante cuando se haga mención a los niños, se hace referencia a los niños y las niñas respondiendo a la perspectiva de género. 
integral de los niños y niñas desde la gestación hasta los 6 años de edad; respondiendo a sus necesidades y características específicas, y contribuyendo así al logro de la equidad e inclusión social en Colombia" (Conpes y DNP, 2007, p. 28), lo cual permite tener una visión amplia de la atención integral, ya que no se queda en la satisfacción de las necesidades básicas sino que se ocupa de la formación, el aprendizaje y el desarrollo integral de los niños.

La ciudad de Medellín, bajo la administración de Sergio Fajardo Valderrama (2004-2007), preocupada por la población infantil de los o a 6 años de edad, creó en el año 2004 el Programa Buen Comienzo, como estrategia de gobierno para atender no sólo las necesidades básicas de alimentación, cuidado, nutrición, salud, entre otras, sino también aquellas relacionadas con la educación, el aprendizaje y el desarrollo de la primera infancia, de los niveles ${ }^{4}$ y 2 del Sisbén 5 y población en situación de desplazamiento, y del nivel 3 del Sisbén, previa documentación del grado de vulnerabilidad ${ }^{6}$. Dados los resultados de dicho programa, se convirtió en Política Pública Municipal mediante el Acuerdo 58 de 2011, reglamentado en el Decreto 01277 de 2013, lo cual permite una continuidad en la atención integral y una protección permanente de los niños como sujetos sociales y titulares de los derechos consagrados en los tratados internacionales, en la Constitución Política y en el Código de la Infancia y la Adolescencia; y cuya función es garantizar una atención que se expanda a todas las esferas de la sociedad a partir de una articulación intersectorial e interinstitucional, reconociendo a los niños como sujetos de derechos y la infancia como una categoría social (Casas, 2006).

Esta política municipal se convirtió en una herramienta importante puesto que muchos de los niños pertenecientes a estos niveles deben estar al cuidado de personas externas a su núcleo familiar (docentes, auxiliares docentes, madres comunitarias, directivos y profesionales de apoyo), y estas personas, que están a cargo de los hogares infantiles, hogares comunitarios, escuelas o preescolares entran a cumplir un papel preponderante; todas estas personas, a quienes se les denomina "agentes educativos", son responsables por la atención y protección de los niños en el marco de los programas y políticas públicas de atención integral a la primera infancia, y deben de tener un nivel de formación mínimo y un conocimiento profundo de la infancia para hacerse cargo de los niños, a fin de que el proceso formativo y de atención integral tenga un impacto positivo en su desarrollo multidimensional e integral y en los procesos de educación inicial.

\footnotetext{
4. Los niveles del Sisbén, para atender a los niños, son retomados de la Política de Atención Integral a la Primera Infancia de Medellín, aprobada en el año 2011.

5. Según el Departamento Nacional de Planeación-DNP de Colombia, el Sisbén es el Sistema de Identificación de Potenciales Beneficiarios de Programas Sociales, que por medio de un puntaje clasifica a la población de acuerdo con sus condiciones socioeconómicas.

6. Según la Declaración Universal de los Derechos Humanos en 1948, la situación de vulnerabilidad está relacionada con aquellas personas o grupos de personas que, por razones inherentes a su identidad o condición y por acción u omisión de los organismos del Estado, se ven privados del pleno goce y ejercicio de sus derechos fundamentales y de la atención y satisfacción de sus necesidades específicas.
} 
El proyecto surge, por tanto, de la necesidad de apoyar las políticas públicas de primera infancia que existen en la ciudad de Medellín (Colombia), puntualmente el Programa Buen Comienzo, a través de un asunto tan crucial, como lo son los agentes educativos que atienden a la primera infancia, reconociendo que el concepto de infancia no es único, ya que depende de las representaciones sociales que tiene cada cultura con relación a ella, y de los momentos históricos de la humanidad. De acuerdo con los planteamientos de Alzate (2002, p. 2):

La concepción de la infancia guarda coherencia con la sociedad vigente. Los principios de organización religiosa y militar presentes en períodos como el siglo XII y XIII dan origen a los niños de las cruzadas. Los principios de organización educativa y científica del siglo XVII y XVIII dan origen al niño escolar. Los principios de organización industrial dan origen a los niños trabajadores y a los aprendices del siglo XIX. Los principios de organización familiar dan origen al hijo de familia que realiza todas sus actividades en el hogar bajo la tutela de los padres. El fortalecimiento del Estado da origen a los hijos del estado, niños que desde muy pequeños pasan de manos de sus padres a las de un personal especializado que se hace cargo de ellos en guarderías y jardines infantiles, como se ve actualmente. Esta misma situación se observa en las instituciones que se encargan de la protección del niño: de instituciones masivas tipo cuartel o convento se pasa a la institución escuela, institución taller o institución hogar.

Representaciones sociales (Casas, 2006) ampliamente compartidas sobre la infancia que nos permiten comprender las interrelaciones e interacciones sociales que establecemos en cada sociedad con dicha población, que están estrechamente ligadas con la cultura y los momentos históricos de cada sociedad y que se fueron construyendo en América Latina desde el proceso de colonización y transformaron las prácticas y concepciones que tenían las culturas indígenas que habitaban el territorio latinoamericano con respecto a la infancia (Rodríguez y Mannarelli, 2007). Lo anterior hizo que se incorporaran prácticas eurocéntricas, como el infanticidio, el abandono, la ambivalencia y la intrusión, recurrentes desde la Antigüedad hasta el siglo XVIII (De Mause, 1991).

Además de la concepción histórica de infancia, es necesario reconocer los procesos de desarrollo socioculturales basados en los postulados de Vigostsky (1979, citado por Lucci, 2006), y que están relacionados tanto con un nivel social como individual para generar espacios de interrelaciones pertinentes, donde no solo el ambiente sea el que propicie espacios diversificados para el aprendizaje (Coleman, 1998; Lin, 1999), sino que el niño sea un sujeto activo en los procesos poniendo en juego todo su potencial cognitivo, social, afectivo, comunicativo y corporal.

Conocer sobre las concepciones de infancia, sus procesos de desarrollo y su construcción como población sujeto de derechos, permitirá construir planes de acción y de actualización para los agentes educativos a fin de contribuir a su formación de manera más acertada, teniendo en cuenta las características, las funciones que desempeñan, los asuntos que pueden ser de su interés, y así aportar a la cualificación de las interacciones de ellos con los niños, asunto nodal y de algún modo determinante 
en el mejoramiento de las instituciones, los contextos y los procesos educativos en la primera infancia. Con este propósito se plantea el siguiente interrogante: ¿cuáles serán las características del perfil profesional de los agentes educativos que atienden primera infancia en la Zona 1 (Nororiental) y Zona 2 (Noroccidental) de la ciudad de Medellín, enfocados en el conocimiento de la infancia?

Respecto a los agentes educativos y su formación profesional, Simarra y Pereira (2010) plantean que en la actualidad los agentes educativos siguen formándose bajo los parámetros conceptuales tradicionales, con la idea de maestro del siglo $\mathrm{XX}$, con gran vocación y con habilidad técnica para ejecutar estrategias y se deja de lado la formación académica; destacan que "en Colombia no es posible hablar de un agente educativo como un sujeto universal, sino que es imprescindible hablar de un imaginario pedagógico diverso" (Simarra y Pereira, 2010).

Conscientes de la responsabilidad social que tenemos los adultos con los niños, se consideró importante realizar una investigación enfocada en los agentes educativos que atienden la primera infancia, con el fin de identificar el perfil profesional y las interacciones que tiene dicha población desde sus concepciones. Por ello les otorgamos a los agentes educativos un papel fundamental en dicho proceso investigativo, pues son ellos quienes de manera directa permiten que la atención que se le brinda a la infancia en la ciudad de Medellín sea integral y de calidad, con un enfoque de derechos y de responsabilidad social.

Teniendo en cuenta el anterior marco de referencia que permitió el desarrollo del proyecto entre los años 2012-2013, en el presente artículo se analizan algunos de los resultados obtenidos en la caracterización del perfil profesional de los agentes educativos que atienden primera infancia en la Zona 1 (Nororiental) y Zona 2 (Noroccidental) de la ciudad de Medellín, con relación a su conocimiento de la infancia desde una perspectiva histórica, política, de desarrollo y de derechos, y cómo dicho conocimiento o desconocimiento influyen en la atención educativa integral de la primera infancia de Medellín. Para lograr dicho análisis, el artículo se fundamenta en diversos referentes teóricos y normativos, como las políticas públicas de atención a la primera infancia que se han gestado en el ámbito nacional y municipal, y algunos artículos académicos y científicos y libros donde se reconoce la infancia desde una perspectiva de derechos, de desarrollo, histórica y política.

\section{Metodología}

La investigación se enmarcó en un paradigma cuantitativo de tipo no experimental y descriptivo correlacional, ya que se caracterizó y analizó el perfil profesional de los agentes educativos que atienden primera infancia en la Zona 1 Nororiental y la Zona 2 Noroccidental de la ciudad de Medellín?.

\footnotetext{
7. La ciudad de Medellín (Antioquia, Colombia) se encuentra dividida en siete zonas: zona 1 nororiental, zona 2 noroccidental, zona 3 centroriental, zona 4 centroccidental, zona 5 suroriental, zona 6 suroccidental y zona 7 distrito rural; y estas a su vez se dividen en comunas, sumando un total de 16 comunas. Las zonas se emplean para agrupar las comunas según su ubicación dentro de la ciudad.
} 
Para la caracterización y el análisis del perfil profesional se utilizó una entrevista estructurada, a la cual se le realizó pilotaje y análisis entre grupos de pares investigadores antes de ser aplicada a los sujetos participantes de la investigación. Este instrumento lo diligenciaron los agentes educativos pertenecientes a instituciones oferentes del Programa Buen Comienzo y a instituciones oficiales y privadas, a partir de veinticinco ítems en los que se preguntó por su formación y conocimiento acerca de la infancia. La muestra se estableció por medio de la base de datos del Programa Buen Comienzo y de los núcleos educativos de la ciudad, se tomó una muestra estratificada de 253 agentes educativos entre los que se encuentran: docentes, auxiliares docentes, madres comunitarias, directivos docentes y profesionales de apoyo, ubicados en las zonas ya mencionadas. El instrumento se aplicó de forma aleatoria en las dos zonas en dos meses, abril y mayo, del año 2013.

Las subvariables contempladas en el instrumento que indaga por el perfil profesional y que guardan relación con la perspectiva histórica, política, de desarrollo y de derechos, dentro de la variable de conocimiento de la infancia, fueron:

- Concepción e historia de la infancia

- Conocimiento de la política y el desarrollo

- Conocimiento de los derechos

\section{Resultados y discusión}

Hablar de un perfil profesional de los agentes educativos que atienden primera infancia en la Zona 1 Nororiental y la Zona 2 Noroccidental de la ciudad de Medellín, es hablar de sus características considerando su nivel de formación y el conocimiento que tienen de la infancia desde una perspectiva histórica, política, de desarrollo y de derechos. Pero ese perfil profesional también se caracteriza por ser propio de cada uno de los agentes, ya que se reconstruye permanentemente en las interrelaciones que se establecen con los niños en la praxis educativa.

El perfil se caracteriza por ser orientador y no prescriptivo, ya que las tendencias actuales apuntan hacia la concepción de perfiles polivalentes abiertos y dinámicos. De allí la necesidad de formar un docente reflexivo, crítico e investigador, lo cual constituye actualmente una alternativa adecuada si se quiere contar con profesionales que incorporen en el ámbito de la educación inicial habilidades y conocimientos para diseñar, desarrollar, evaluar y formular estrategias y programas de intervención educativa en contextos socio-educativos y culturales cambiantes. (Ministerio de Educación, Cultura y Deportes, 2001, p. 241)

A partir de reconocer la formación como el eje central que permite la constitución de los sujetos en un campo social y cultural, y teniendo en cuenta la formación de los agentes educativos que atienden la primera infancia en la ciudad de Medellín, es necesario que el proceso de interacción que se establezca con la infancia parta de su reconocimiento profundo desde diferentes perspectivas, pero sobre todo que se construya una concepción clara sobre ella, ya que de esto depende el modo de relacionarse con esta población y la garantía de sus derechos desde un enfoque de integralidad. 


\section{Concepción e historia de la infancia}

No existe una única concepción sobre la infancia, ya que este concepto depende de las representaciones sociales de cada cultura con relación a ella y de los momentos históricos de la humanidad (Alzate, 2002).

Así, a partir de la subvariable que indaga por el conocimiento acerca de la infancia, se observa que entre el 33,3\% y el 50,7 \% de los agentes educativos pertenecientes a los oferentes del Programa Buen Comienzo, las instituciones oficiales y privadas conciben a los niños y niñas como sujetos de derechos, los demás porcentajes se distribuyen en una concepción como objetos de protección, agentes-activos y agentespasivos (ver Figura 1). Con relación a lo anterior, es posible considerar que los agentes educativos de esta investigación se encuentran en un nivel promedio en términos de sus concepciones sobre la infancia.

Los agentes educativos que hacen parte del Programa Buen Comienzo evidencian un mayor conocimiento de la infancia como población sujeto de derechos con relación a los agentes de las instituciones oficiales y privadas, lo cual puede deberse a que se encuentran en una relación más estrecha con la Política Pública de Atención Integral a la Primera Infancia de Medellín, y además participan en eventos académicos y procesos formativos permanentes, donde se parte del reconocimiento de los niños como sujetos de derechos con base en la Convención de los Derechos del Niño de 1989, la Constitución Política de Colombia de 1991 y el Código de la Infancia y la Adolescencia de 2006.

Es necesario hacer un estudio para indagar por qué los agentes educativos que pertenecen a instituciones oficiales y privadas y algunos a los oferentes de Buen Comienzo, aún tienen una visión de los niños y niñas como agentes-activos, agentespasivos o como objetos de protección, lo cual puede deberse a los niveles de formación, a un desconocimiento de la evolución histórica que ha tenido la categoría de infancia, de los movimientos sociales a favor de ella, de las políticas, programas y proyectos que se han gestado para garantizar sus derechos, o tal vez porque siguen considerando la infancia como una etapa de fragilidad y de carencias y desconocen que, como en todas las etapas de desarrollo del ser humano, se poseen potencialidades y capacidades susceptibles de desarrollo por medio de relaciones con los objetos y los sujetos. 


\section{Concepciones de la Infancia}

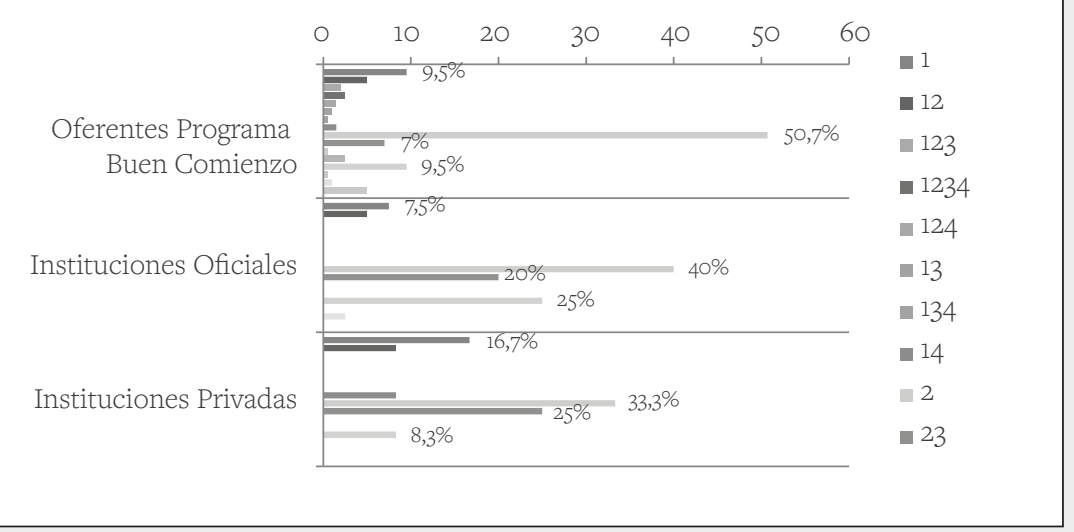

Figura 1. Opinión de los agentes educativos por tipo de institución respecto a las concepciones de la infancia.

(1) objeto de protección, (2) sujeto de derechos, (3) agente-activo, (4) agente-pasivo.

Fuente: Elaboración propia.

A partir de la concepción de los agentes educativos sobre la infancia, se indagó por el conocimiento que tienen de su configuración histórica, y para ello se tuvieron en cuenta cuatro preguntas esenciales a fin de identificar si tienen un conocimiento respecto al proceso histórico que ha tenido dicha población. Se observa que en la primera pregunta: ¿considera usted que la infancia ha tenido un significado relevante para la sociedad en todas las épocas?, entre un $55,2 \%$ y un 72,5\% de los agentes educativos consideran que la infancia NO ha tenido un significado relevante para las sociedades en todas las épocas (ver Figura 2). Los agentes educativos de las instituciones oficiales son los que reportan el mayor porcentaje, en tanto que entre los agentes educativos de los oferentes del Programa Buen Comienzo y de las instituciones privadas, no se observa un margen de diferencia amplio con los que consideran que la infancia sí ha tenido un significado relevante en todas las épocas. 


\section{¿Considera usted que la infancia ha tenido un significado relevante para la sociedad en todas las épocas?}

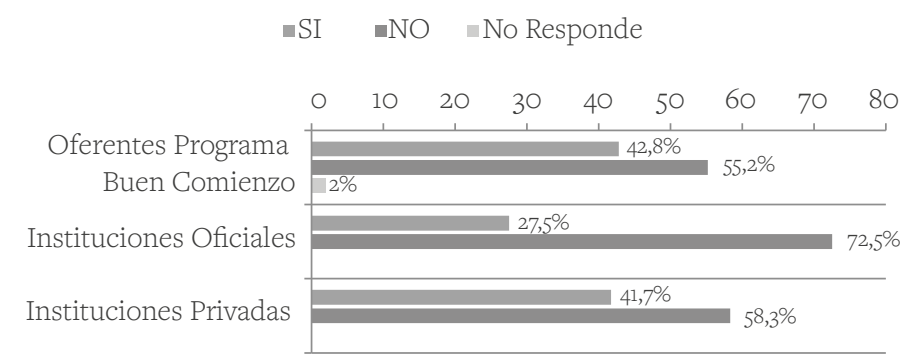

Figura 2. Opinión de los agentes educativos por entidad respecto al significado relevante de la infancia para la sociedad en todas las épocas.

Fuente: Elaboración propia.

En la segunda pregunta: ¿puede decirse que para todas las culturas la infancia tiene el mismo significado?, entre un $81,6 \%$ y un $92,5 \%$ de los agentes educativos consideran que la infancia NO tiene en todas las culturas el mismo significado, y existe una tendencia marcada entre los tres tipos de instituciones (ver Figura 3).

\section{¿Puede decirse que para todas las culturas la infancia tiene el mismo significado?}

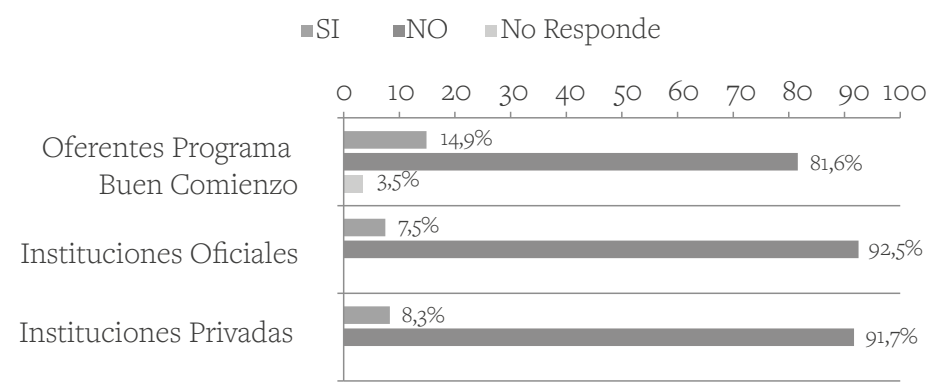

Figura 3. Opinión de los agentes educativos por tipo de institución respecto al significado de la infancia para todas las culturas.

Fuente: Elaboración propia. 
Se observa que en la tercera pregunta, ¿tiene conocimiento de la influencia de otras culturas en América Latina que han transformado positivamente la concepción de infancia?, no existe una tendencia entre los tres tipos de instituciones, ya que entre un $52,2 \%$ y un $55 \%$ de los agentes educativos de los oferentes del Programa Buen Comienzo y las instituciones oficiales manifiestan que Sí tienen conocimiento de la influencia positiva de otras culturas en la transformación de la concepción de infancia en América Latina, mientras que un 83,3\% de los agentes educativos de las instituciones privadas dicen NO tener conocimiento de dicha influencia (ver Figura 4).

¿Tiene conocimiento de la influencia de otras culturas en América Latina que han transformado positivamente la concepción de infancia?

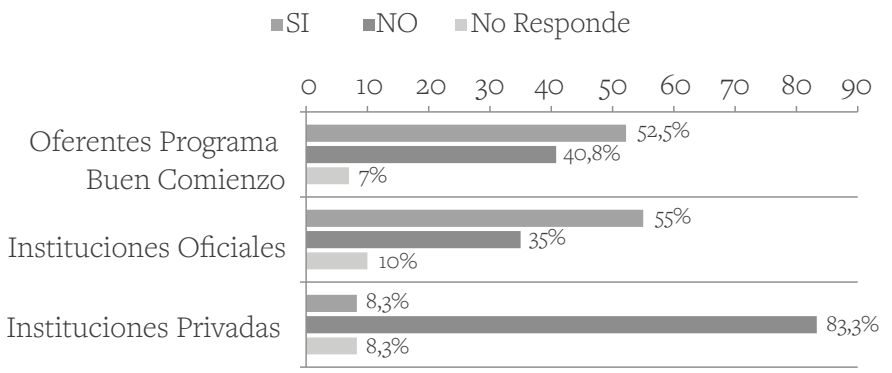

Figura 4. Opinión de los agentes educativos por tipo de institución respecto al conocimiento de la influencia de otras culturas en América Latina en la transformación positiva de la concepción de infancia.

Fuente: Elaboración propia.

Finalmente, en la cuarta pregunta, ¿cree usted que las condiciones de infanticidio, abandono, ambivalencia e intrusión se han superado en la época actual?, existe una tendencia entre un 75,1\% y un 91,7\% de los agentes educativos del Programa Buen Comienzo, de las instituciones oficiales y privadas que consideran que las condiciones de infanticidio, abandono, ambivalencia e intrusión NO se han superado en la época actual (ver Figura 5). 
¿Cree usted que las condiciones de infanticidio, abandono, ambivalencia e intrusión se han superado en la época actual?

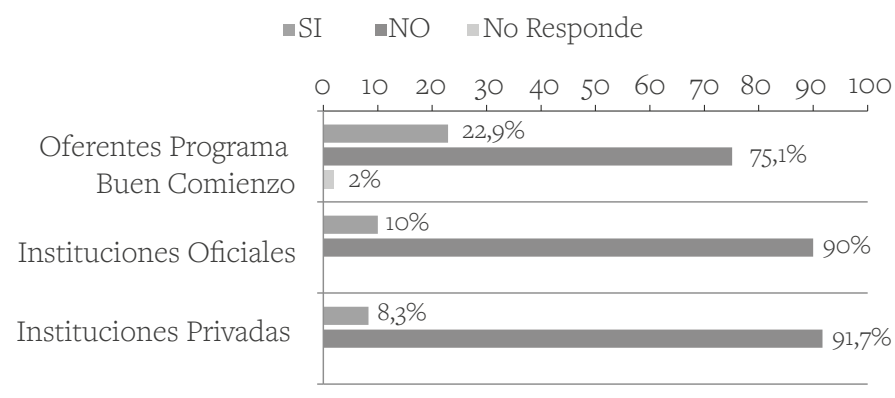

Figura 5. Opinión de los agentes educativos por tipo de institución respecto a la superación de infanticidio, abandono, ambivalencia e intrusión en la época actual. Fuente: Elaboración propia.

Si se analizan los anteriores resultados que hacen referencia al conocimiento de la historia de la infancia, queda claro que existen algunas contradicciones de unos resultados con otros. Al relacionar la subvariable sobre la concepción de infancia que tienen los agentes educativos, se encontró que aproximadamente la mitad de los agentes educativos de los tres tipos de institución conciben a los niños como sujetos de derechos, lo cual implica necesariamente conocer el devenir histórico que ha marcado a la población infantil, pero al responder a las cuatro preguntas formuladas se evidencia que no hay claridad respecto a la historia de la infancia.

Primero, cuando se pregunta si la infancia ha tenido un significado relevante para la sociedad en todas las épocas, aunque los porcentajes más amplios se ubican en el NO, muchos agentes educativos aún consideran que Sí ha tenido el mismo significado, lo que evidentemente muestra un desconocimiento respecto a las representaciones sociales ampliamente compartidas sobre la infancia, que permitan comprender las interrelaciones e interacciones sociales que establecemos en cada sociedad con dicha población y que están estrechamente ligadas con la cultura y los momentos históricos de cada sociedad.

Segundo, al indagar si en todas las culturas existe el mismo significado con respecto al concepto de infancia, se encuentra que en porcentajes muy amplios los agentes educativos de los tres tipos de instituciones consideran que NO, lo cual evidenciaría que tienen claro que cada sociedad y cultura construyen sus propias concepciones según las creencias y costumbres, sin embargo, esta respuesta es contradictoria frente a la de la anterior pregunta, en la cual un porcentaje significativo responde que en 
todas las épocas las sociedades SÍ han tenido el mismo significado sobre la infancia. Es decir, por un lado consideran que no todas las culturas tienen el mismo significado de la infancia, pero, por otro, que todas las sociedades en todas las épocas han tenido el mismo significado de la infancia.

Tercero, al preguntar por la influencia positiva de otras culturas en la concepción de infancia en América Latina, los resultados muestran que los agentes educativos que trabajan con Buen Comienzo y las instituciones oficiales manifiestan conocer la influencia positiva que han tenido otras culturas en la concepción de infancia en América Latina, en oposición a lo que opinan los agentes educativos de las instituciones privadas, los cuales consideran que otras culturas no influyeron positivamente en la concepción de infancia en Latinoamérica. Lo anterior evidencia que tanto los agentes educativos del Programa Buen Comienzo como de las instituciones oficiales no tienen claridad del proceso de colonización que América Latina vivió, y por ende de la transformación de las prácticas y concepciones que tenían las culturas indígenas que habitaban el territorio latinoamericano con respecto a la infancia.

Por último, al indagar por la superación en la época actual de condiciones como infanticidio, abandono, ambivalencia e intrusión, se encuentra que los agentes educativos de los tres tipos de instituciones consideran que en la actualidad no se han superado estas prácticas en contra de la infancia, lo que permite develar como ellos desde su práctica profesional evidencian cotidianamente que la infancia sigue siendo en la actualidad una población en situación de vulnerabilidad.

Por eso los agentes educativos no pueden generalizar las concepciones que se han tenido sobre la infancia a lo largo de la historia, ya que es evidente que el significado de la infancia no ha sido el mismo en todas las sociedades y culturas en las diferentes épocas. Este conocimiento permite reconocer las concepciones e imágenes de la infancia en diferentes épocas históricas, así como las prácticas a favor o en contra y las características de los contextos familiares, sociales y culturales que la han rodeado, y de este modo llegar a la concepción actual sobre infancia como una categoría social, y de los niños como sujetos de derechos reconocidos mediante la Convención de los Derechos del Niño en 1989, lo que ha generado movilizaciones sociales a favor de su protección, bienestar, educación y participación.

\section{Conocimiento de la política y el desarrollo}

El conocimiento de la política implica necesariamente conocer el marco normativo y legal que dio origen al reconocimiento de los niños como sujetos de derechos, y desde allí el planteamiento de una atención integral a esta población. Algunos de los documentos son: a) Documento Conpes Social 109, que materializa la Política Pública de Primera Infancia “Colombia por la Primera Infancia”, con el fin de garantizar un desarrollo integral de los niños; b) Guías del Ministerio de Educación Nacional que fundamentan los procesos educativos, entre ellas la Guía 35 "Ruta de Atención Integral a la Primera Infancia”, la Guía 10 "Desarrollo Infantil y Competencias en la Primera 
Infancia”, y la Guía 13 “Aprender y Jugar, Instrumento Diagnóstico de Competencias Básicas en Transición”; c) Áreas del Derecho (protección, participación, vida y supervivencia, desarrollo y educación inicial), las cuales recopilan los derechos de los niños consagrados en la Convención de los Derechos del Niño y la Constitución Política de 1991; d) Ley 1098 de 2006, Código de la Infancia y la Adolescencia, cuya finalidad es garantizar a los niños su pleno y armónico desarrollo, por medio del establecimiento de normas para la protección integral de la infancia. Otros documentos son la Convención de los Derechos del Niño de 1989, resoluciones, decretos, programas, proyectos, planes y estrategias que propendan por la atención de los niños desde los principios de integralidad y corresponsabilidad.

Se observa que no existe una tendencia entre los tres tipos de instituciones respecto de la subvariable que indaga por el conocimiento que tienen los agentes educativos de las normas referentes a la atención integral a la primera infancia: un 16,9\% de los agentes educativos del Programa Buen Comienzo conocen la Ley 1098 de 2006 y un 11,4 \%, las áreas de derecho. En cuanto a los agentes educativos de las instituciones oficiales, un $30 \%$ conocen las guías del MEN y la Ley 1098 de 2006, y un 33,3 \% de los de las instituciones privadas conocen las guías del MEN. Los otros porcentajes se distribuyen en las demás opciones de respuesta (ver Figura 6).

$\mathrm{Al}$ analizar estos resultados, se evidencia que no existe una unificación en cuanto a los documentos legales que ellos dicen conocer. El porcentaje más amplio de los agentes educativos del Programa Buen Comienzo se ubican en un conocimiento de la Ley 1098 de 2006 y de las áreas de derecho, lo cual es lógico en el sentido que ellos pertenecen de manera directa a la política pública de atención integral a la primera infancia, de la cual ambos documentos son el sustento, ya que, por un lado, la Ley 1098 plantea el principio de corresponsabilidad entre familia, sociedad y Estado, y la importancia que tienen los primeros años de vida en el desarrollo cognitivo, social, afectivo y comunicativo del ser humano, y por otro lado, porque las áreas de derecho son las que sustentan las políticas públicas, ya que a partir de ellas se materializa la atención en salud, nutrición, protección, educación, ciudadanía y desarrollo integral de la primera infancia.

El mayor de los porcentajes entre los agentes educativos de las instituciones oficiales y privadas, por su parte, dicen conocer las guías del Ministerio de Educación Nacional, lo cual se explica porque ellos pertenecen no al ámbito de la educación inicial regida por las políticas públicas de primera infancia, sino al ámbito de la educación formal, donde los lineamientos que plantea el Ministerio son los que rigen el funcionamiento de las instituciones y la práctica pedagógica y educativa de los agentes. 


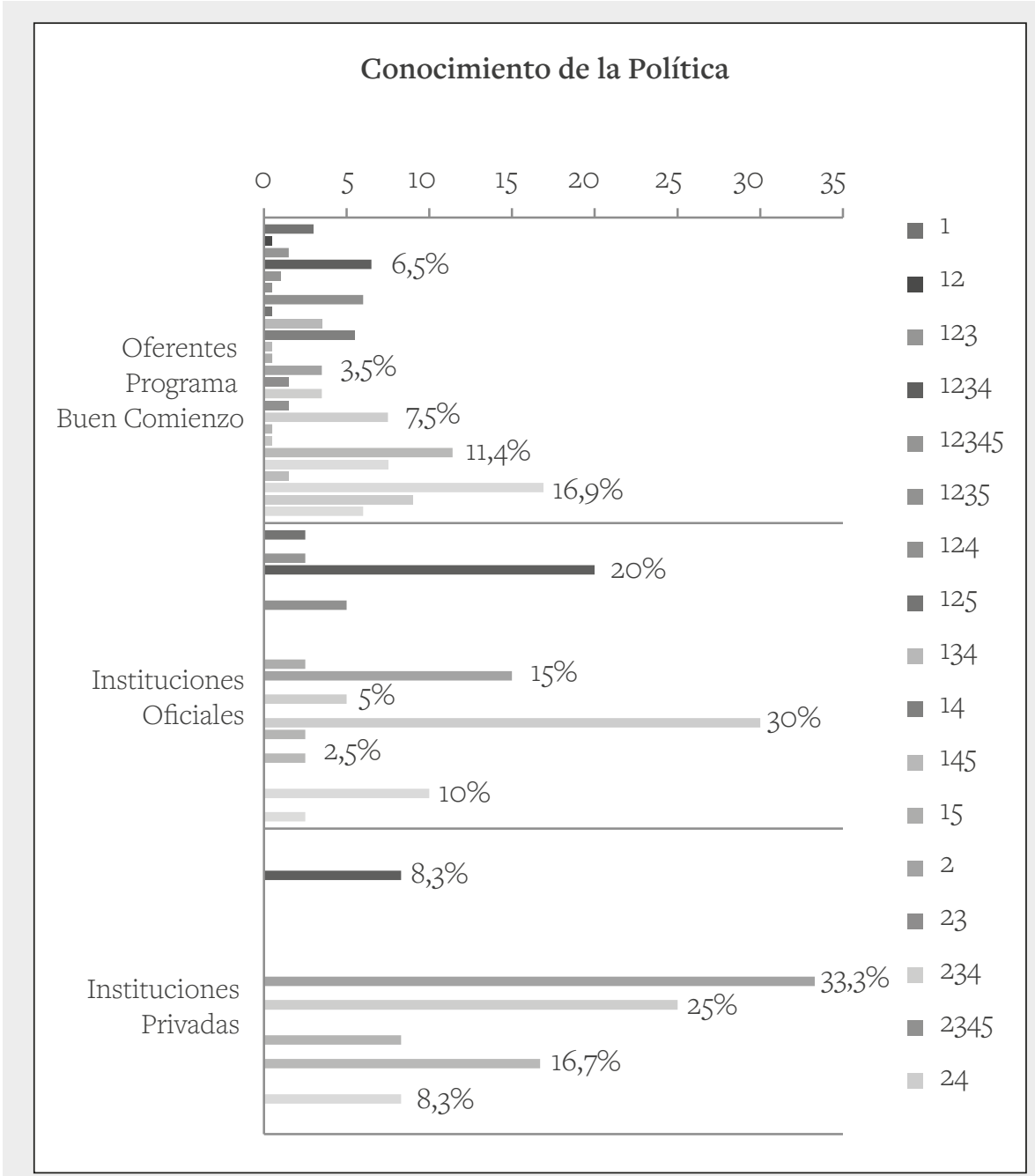

Figura 6. Opinión de los agentes educativos por tipo de institución respecto al conocimiento de las políticas o normas referentes a la Atención Integral a la Primera Infancia.

(1) Conpes 109, (2) Guías MEN, (3) Áreas de Derecho, (4) Ley 1098 de 2006, (5) Otra.

Fuente: Elaboración propia.

Esimportante destacar que dentro de estos documentos que sustentany complementan la Política Pública de Atención Integral a la Primera Infancia, el desarrollo se concibe (MEN, 2009a) como un proceso de reconstrucción y reorganización permanente, de interacción consigo mismo y con el contexto, que no es lineal sino complejo y caracterizado por continuos avances y retrocesos que no tienen un principio definido, ya que se presenta y manifiesta desde la gestación, ni tienen un final diferente a la muerte del individuo. 
Se observa que con base en la subvariable que indaga por el conocimiento que tienen los agentes educativos frente a la teoría del desarrollo que sustenta la política pública de atención integral a la primera infancia, no existe una tendencia entre los tres tipos de instituciones, ya que desde los oferentes del Programa Buen Comienzo y las instituciones privadas entre un $45,3 \%$ y un $50 \%$ de los agentes educativos consideran que en la política pública la teoría del desarrollo que actualmente se reconoce como relevante para el trabajo con la primera infancia es la Teoría Estímulo-Ambiente. Por su parte los agentes educativos de las instituciones oficiales, consideran que la teoría relevante es la Ecológico-Contextual con un 52,5\% (ver Figura 7).

Los agentes educativos del Programa Buen Comienzo y de las instituciones privadas presentan niveles altos de desconocimiento respecto a la teoría del desarrollo que sustenta la Política Pública de Atención Integral a la Primera Infancia, la cual plantea que el desarrollo es un proceso cambiante de reconstrucción y reorganización permanente, en interacción consigo mismo y con el contexto. El desconocimiento de los agentes puede deberse a que no conocen las políticas públicas que se han gestado a nivel nacional y municipal en torno a la primera infancia, lo que puede repercutir en la manera como los agentes educativos planean sus actividades y las desarrollan, y los objetivos que proponen para las mismas, ya que ellos afirman que la teoría relevante en el trabajo con los niños es la de estímulo-ambiente, que se relaciona con los postulados de la teoría sociocultural, la cual plantea el desarrollo del ser humano dentro de un contexto social, es decir, primero se establecen relaciones con el entorno y posteriormente nos desarrollamos.

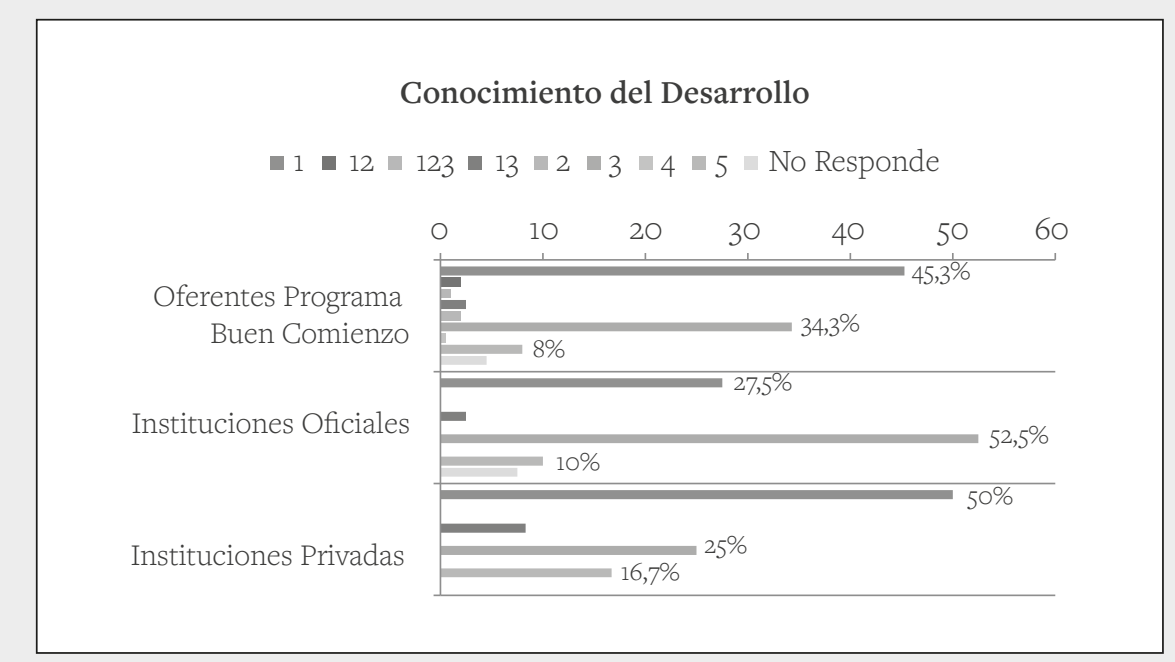

Figura 7. Opinión de los agentes educativos por tipo de institución respecto al conocimiento de la teoría del desarrollo que sustenta la Política Pública de Atención Integral a la Primera Infancia.

(1) Estímulo-Ambiente, (2) Organicista, (3) Ecológico-Contextual, (4) Otra, (5) No Sabe-No Responde. Fuente: Elaboración propia. 
Los agentes educativos, en la medida en que reconocen que actualmente desde la política pública la teoría que sustenta el trabajo con la primera infancia es la ecológicocontextual, en la que se relaciona el desarrollo de los niños con el desarrollo humano desde el capital social, pueden concebirlo tanto desde el nivel micro (individual) como desde una perspectiva macro. Se entiende que a nivel macro el capital social hace referencia a los arreglos institucionales, la confianza y las redes sociales entre grupos étnicos, y que a nivel individual, se refiere al acceso a recursos insertos en una red social en aras de alcanzar un propósito determinado. Partiendo de la base de arreglos mutuos (Coleman, 1998; Lin, 1999) se generan espacios de interrelaciones pertinentes, donde no solo el ambiente propicie espacios diversificados para el aprendizaje, sino que el niño sea un sujeto activo en los procesos, poniendo en juego todo su potencial cognitivo, social, afectivo, comunicativo y corporal.

\section{Conocimiento de los derechos}

La Política Pública de Primera Infancia, además de determinar la teoría relevante en la relación que el agente establece con la infancia, ofrece un marco de referencia en torno a los derechos de los niños, los cuales fueron reconocidos por la Convención sobre los Derechos del Niño en 1989 y permiten brindarles una atención integral, y que son agrupados en cuatro áreas (Alcaldía de Medellín, Decreto 01277 de 2013):

- Vida y supervivencia: es el derecho a la vida, que se entiende como el bienestar físico, psíquico y social, como ejercicio pleno del proceso vital en armonía consigo mismo, con los demás y con el mundo.

- Protección: es el derecho que tienen los niños y las niñas a disfrutar de una vida plena en condiciones que aseguren el respeto de su dignidad y el derecho a ser cuidados y protegidos frente a conductas que atenten contra su desarrollo integral como seres humanos.

- Desarrollo y educación inicial: la educación para la Primera Infancia es un proceso continuo y permanente de interacciones y relaciones sociales de calidad, oportunas y pertinentes que posibilitan a los niños y a las niñas potenciar sus capacidades y adquirir competencias para la vida en función de un desarrollo pleno que propicie su constitución como sujetos.

- Participación: es el reconocimiento que se hace a niños y niñas como protagonistas de su propia vida y de la sociedad creando condiciones y medios para fortalecer una cultura democrática y de ejercicio de sus derechos.

Dentro de la subvariable que indaga por el conocimiento que tienen los agentes educativos de los derechos de la infancia, se tuvieron en cuenta dos preguntas fundamentales para la investigación. Se observa que en la primera pregunta (¿qué tipo de derechos de la infancia conoce?) existe una tendencia en los tres tipos de instituciones, ya que entre un 55,2 \% y un 67,5\% de los agentes educativos dicen conocer solo los derechos fundamentales de la infancia (ver Figura 8). 


\section{¿Qué tipo de derechos de la infancia conoce?}

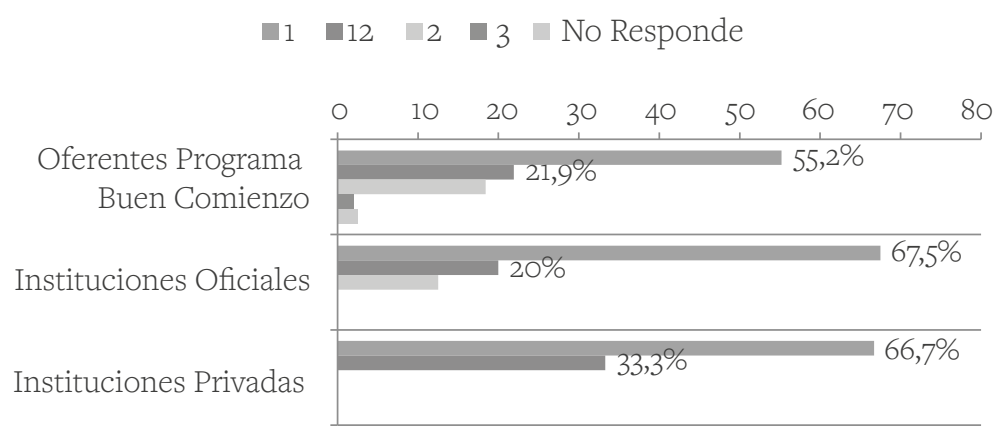

Figura 8. Opinión de los agentes educativos respecto al tipo de derechos de la infancia que conoce. (1) Fundamentales, (2) Áreas de Derechos, (3) No conoce, (4) Otros. Fuente: Elaboración propia.

Se observa que en la segunda pregunta ¿cuáles documentos legales conoce usted?, entre un $25 \%$ y un $47,5 \%$ de los agentes educativos dicen conocer la Constitución Política de Colombia de 1991, como el documento legal que protege los derechos de la infancia (ver Figura 9). 


\section{Conocimiento de la Política}

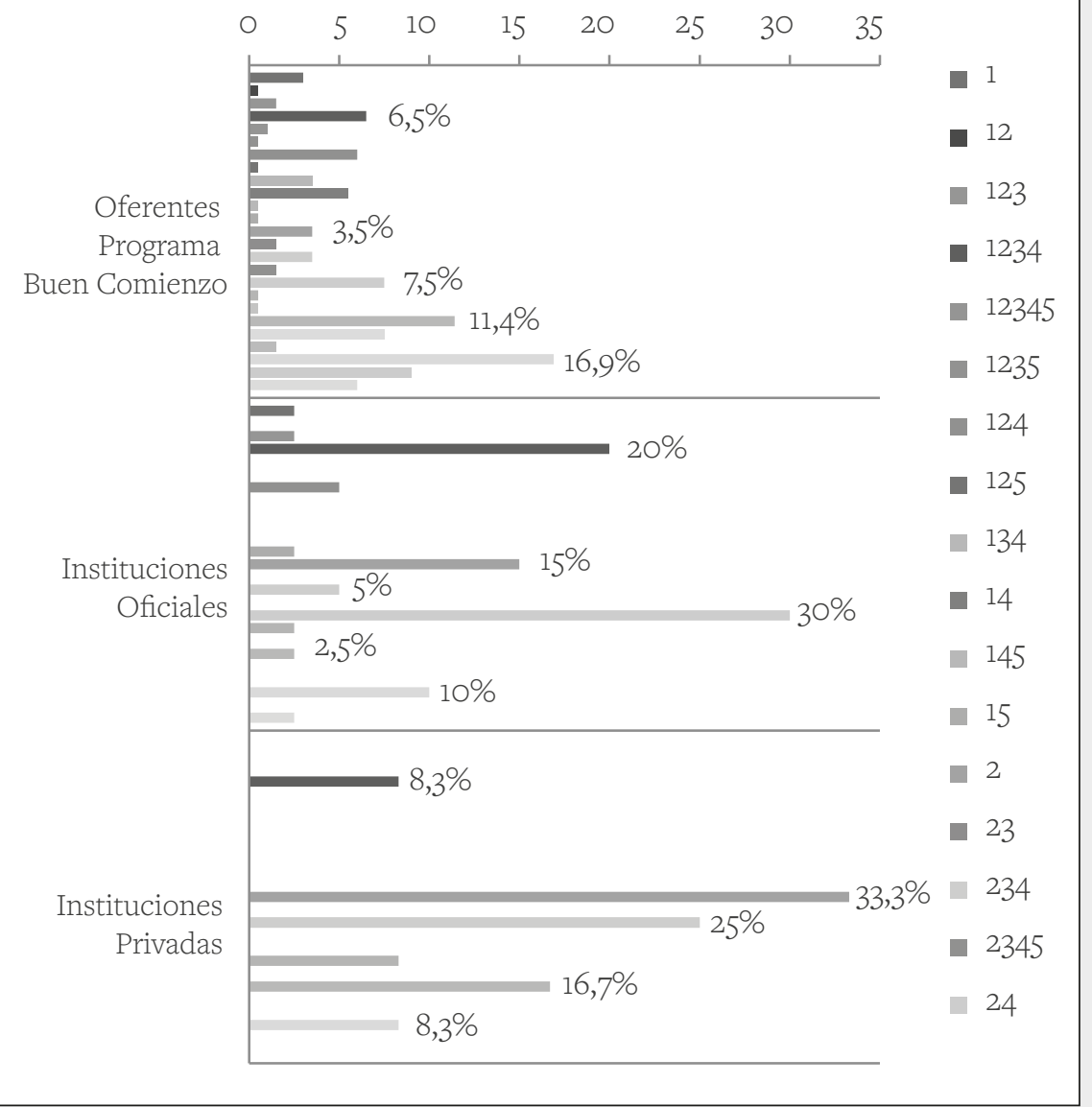

Figura 9. Opinión de los agentes educativos por entidad respecto a los documentos legales que conocen relacionados con los derechos de la infancia.

(1) Constitución, (2) Convención, (3) Protección, (4) Derechos Áreas, (5) No conoce, (6) Otra. Fuente: Elaboración propia. 
Si analizamos los anteriores resultados respecto al conocimiento que los agentes educativos dicen tener de los derechos de los niños, encontramos lo siguiente: en primer lugar, queda claro que en los tres tipos de instituciones se tiene un conocimiento amplio de los derechos fundamentales de los niños, a saber, la vida, la integridad física, la salud y la seguridad social, la alimentación equilibrada, nombre y nacionalidad, tener una familia y no ser separados de ella, el cuidado y el amor, la educación y la cultura, la recreación y la libre expresión de su opinión, consagrados en en el Artículo 44 de la Constitución Política de 1991. Sin embargo, también se revela que los agentes educativos que atienden primera infancia desconocen la existencia de cuatro áreas de derecho (vida y supervivencia, protección, participación, y desarrollo y educación inicial), que fueron estipuladas en la Convención de los Derechos del Niño en 1989, que fue ratificada por Colombia en 1991, la cual recoge los derechos fundamentales de los niños que son el eje central de la Política Pública de Atención Integral a la Primera Infancia en Colombia y en el municipio de Medellín.

En segundo lugar, con relación a la pregunta sobre cuáles documentos legales conocen en relación con los derechos de la infancia, se evidencia que existe coherencia con la pregunta anterior, cuya respuesta predominante fue los derechos fundamentales, en este caso predominó el conocimiento de la Constitución Política, en cuyo Artículo 44 están estipulados los derechos fundamentales de los niños, lo que muestra una vez más el desconocimiento que existe respecto de las áreas de derecho y por tanto de la Convención de los Derechos del Niño.

Lo anterior genera diferentes inquietudes, ya que si se habla de una política pública nacional y una política pública municipal cuya población sujeto son los niños desde la gestación hasta los cinco años de edad, ¿por qué se desconoce la Convención de los Derechos del Niño?, ¿por qué si un alto porcentaje de los agentes educativos los conciben como sujetos de derechos, no se reconocen las áreas de derecho que permiten visibilizarlos como tal desde un enfoque integral? ¿Acaso falta mayor divulgación de la información y los documentos legales por parte de los gobiernos nacional y municipal, o falta mayor compromiso personal y profesional de los agentes educativos por apropiarse de los documentos y por ende de la Política Pública de Atención Integral a la Primera Infancia? Son interrogantes que dejan abiertas posibles posteriores investigaciones que develen por qué los agentes educativos que atienden primera infancia desconocen aspectos fundamentales de la infancia, y que son esenciales para logar una integralidad en la atención y unas interrelaciones pertinentes y de calidad con los niños.

\section{Conclusión}

En el proceso de descripción y análisis de los resultados arrojados en la aplicación del instrumento de perfil profesional a los agentes educativos que atienden primera infancia en la Zona 1 Nororiental y Zona 2 Noroccidental de la ciudad de Medellín, se concluye que el conocimiento de la infancia de los agentes educativos incide en 
las relaciones que se establecen entre agente educativo y niño, ya que es a partir de los procesos de socialización, institucionalizados o no, que se generan procesos de mediación pedagógica que afectan directa o indirectamente el modo de ver y de obrar en el mundo de la vida, para desarrollar la capacidad de expresión, movilizar pensamientos y potenciar acciones consigo mismo, con el otro y con lo otro, para integrarse a una cultura y a su vez transformarla.

En consecuencia, la caracterización y el análisis del perfil profesional en la investigación dan cuenta de un desconocimiento no generalizado de la categoría de infancia desde una perspectiva histórica, política, de desarrollo y de derechos, que repercute en la atención integral de los niños, lo cual puede deberse a posturas sociales aceptadas, es decir que el Estado y la sociedad en general siguen aceptando y legitimando los conocimientos de los agentes educativos por el solo hecho de trabajar con la infancia; puede deberse también a posturas personales-actitudinales que no asumen responsabilidades individuales para actualizarse, o a una postura conductualprocedimental, pues se siguen pautas y patrones establecidos desde años atrás y se desconocen los avances teóricos, históricos, políticos, sociales y educativos con relación a la infancia.

Por lo tanto, el perfil profesional de los agentes educativos de primera infancia debe ir en correspondencia con un proyecto histórico-pedagógico, es decir, debe reflejar el arquetipo de ser humano que se anhela formar y el tipo de ciudadanía a la que se aspira en un momento determinado, pues esto condiciona las actividades y orienta los esfuerzos que se llevan a cabo en los niveles personal, social y gubernamental a fin de seguir en el reconocimiento de la infancia como una categoría social, y de los niños como sujetos de derechos.

\section{Referencias}

Alcaldía de Medellín. Decreto 01277 del 5 de julio de 2013, “Por el cual se reglamenta el Acuerdo 58 de 2011, mediante el cual se adoptó la Política Pública de Atención Integral a la Primera Infancia Buen Comienzo, se desarrolló un Sistema de Atención Integral y se modificó el Acuerdo 14 de 2004”. Gaceta Oficial, N. ${ }^{\circ} 4176$.

Alzate, M. (2002). Concepciones e imágenes de infancia. Revista de Ciencias Humanas, (28). Recuperado de http://repository.unad.edu.co/ bitstream/10596/4863/1/514517\%20infancia.pdf

Asamblea Nacional Constituyente (1991). Constitución Política de Colombia. Bogotá, D.C.

Casas, F. (2006). Infancia y representaciones sociales. Política y Sociedad, 43(1), 2742. Recuperado de http://revistas.ucm.es/index.php/POSO/article/view/23779

Coleman, J. (1990). Foundations of Social Theory. Cambridge, Mass.: Harvard University Press. 
Concejo de Medellín. Acuerdo 58 de 2011. Por medio del cual se adopta la Política Pública de Atención Integral a la Primera Infancia Buen Comienzo, se desarrolla un Sistema de Atención Integral y se modifica el Acuerdo 14 de 2004. Recuperado de https://medellin.edu.co/documentos/497-acuerdo-058de-2011/file

Congreso de la República de Colombia. Ley 1098 del 8 de noviembre de 2006, "Por la cual se expide el Código de Infancia y Adolescencia”. Diario Oficial, N 46.446.

Consejo Nacional de Política Económica Social (Conpes) y Departamento Nacional de Planeación (DNP) (2007). Documento Conpes 109- Política Pública Nacional de Primera Infancia “Colombia por la Primera Infancia”. Bogotá: DNP. [Versión digital].

De Mause, Ll. (1991). Historia de la infancia. Madrid: Editorial Alianza Universidad.

Lin, N. (1999). Inequality in Social Capital: Evidence from urban China. Creation and returns of social capital in education and labor markets. Center for Research in Experimental Economics and Political Decision Making/University of Amsterdam, Institute of Information and Computing Sciences (ICS)/ University of Groningen and ICS/Utrecht University.

Lucci, M. (2006). La propuesta de Vygotsky: la psicología socio-histórica. Revista de Currículum y Formación del Profesorado, 10(2). Recuperado de http://www. ugr.es/ recfpro/rev102COL2.pdf

Ministerio de Educación Nacional de Colombia (MEN) (2009a). Desarrollo Infantil y Competencias en la Primera Infancia. Documento N. ${ }^{\circ} 10$. Bogotá, D.C. [Versión digital].

Ministerio de Educación Nacional de Colombia (MEN) (2009b). Guía Operativa para la Prestación del Servicio de Atención Integral a la Primera Infancia. Guía N. ${ }^{\circ} 35$. Bogotá, D.C.

Ministerio de Educación Nacional de Colombia (MEN) (2010). Aprender y Jugar, Instrumento Diagnóstico de Competencias Básicas en Transición. Documento N. ${ }^{\circ} 13$ : Bogotá, D.C.

Ministerio de Educación, Cultura y Deportes de Venezuela (2001). Aproximación al perfil del docente para la educación preescolar o inicial. EDUCERE, Intervías Educativas, 5(14), 241-244. Recuperado de http://www.redalyc.org/ pdf/356/35601419.pdf

Rodríguez, P. y Mannarelli, M. (2007). Historia de la infancia en América Latina. Bogotá: Universidad Externado de Colombia.

Simarra, J. (2010). Panorama de las Políticas Públicas de Primera Infancia en Colombia. En Miscelanea Comillas, 68(132), 397-417. Recuperado de https:// revistas.upcomillas.es/index.php/miscelaneacomillas/article/viewFile/844/713

Simarra, J. y Pereira, S. (2010). Formación de agentes educativos institucionales y comunitarios en Colombia. Estrategias clave de la educación inicial.

Unicef (2006 [1989]). Convención sobre los Derechos del Niño. Madrid: Unicef. Recuperado de https://www.un.org/es/events/childrenday/pdf/derechos.pdf 
Los seres humanos

no son sólo socializados,

sino que se socializan

a símismos.
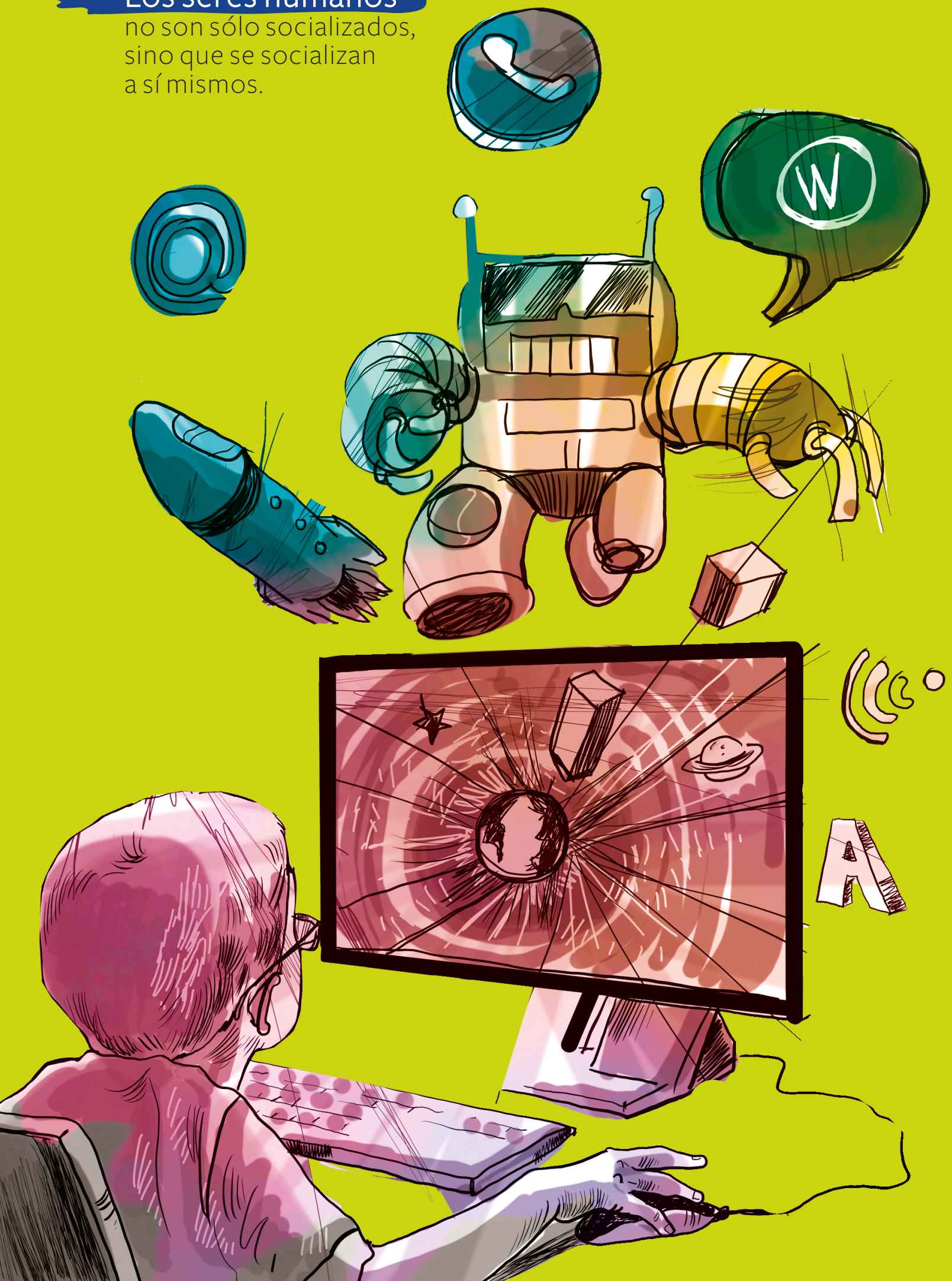